\title{
Examine the optimal position of controls and display in computer numerical control machines
}

DOI:10.36909/jer.ICMMM.12357

\author{
K. Muthukumar*, T. Jishin Jayan \\ Industrial Safety Engineering, Department of Mechanical Engineering, Bannari Amman \\ Institute of Technology, Sathyamangalam - 638401. India.
}

*Email: muthukumarkm@bitsathy.ac.in; Corresponding Author.

\begin{abstract}
In Engineering Industries suffering due to industrial wound and ill health, of the Computer Numerical Control machines operators are in the increasing trend, in the subjective analysis which we carried out for the CNC machine, the operators expressing the discomfort at the neck, upper back, lower back, shoulder, and arm because of working with the keys in the controls and viewing the display. The aim of this examination is to identify the most favourable location of control and display through various muscles that activate while performing in CNC machine operations. We introduce surface Electromyogram (EMG) to determine the muscle activity and deliberate on plane of the body close to respective muscles of an operator.

The muscle activity measured for all the twenty subjects, at five different levels to find out the best optimal location for controls and display to establish the findings of the subjective study. Though there is no clear trend when all the subjects are aggregated, it is seen that 90 $\mathrm{cm}-100 \mathrm{~cm}$ be the optimum range for the midpoint of the control panel and $143 \mathrm{~cm}-148 \mathrm{~cm}$ appears to be the optimum range for the midpoint of the display. Since changes in muscle activity are comparatively small for all the six muscles taken for study, however, the effect of cumulative activity borne over a shift, week, month, and year are to be considered. Muscle activity may increase in repetitive head/finger movements. These combined effects are to be captured for the ergonomic design of the CNC operator interface.
\end{abstract}

Keywords: controls; display; electromyogram; muscular distress; optimal height 


\section{INTRODUCTION}

In Engineering Industries usage of Computer Numerical Control machines are in the increasing trend, and suffering due to industrial wound and ill health, of those operators also in a higher order, in the subjective analysis which we carried out for the CNC machine, the operators expressing the discomfort at the neck, upper back, lower back, shoulder, and arm because of working with the keys in the controls and viewing the display.

This examination is to find and suggest an optimum position to prevent the discomfort of the operators. Work-related Musculoskeletal Disorders (WRMSDs) rise with job pressure or work strain are completed, in a fraction, during surplus muscular stress (Bernard et al., 1993; Faucett and Rempel, 1994; Sauter and Swanson, 1996). For the welders, the location, replication, and extra time add to the all the effort than the performance. For CNC workers, replication and time added further to all the action than the location and activities. The contribution of the position to all the attempts made by the welder is superior to the CNC operators. Alternatively, the connection of force is lesser for welders than for the CNC workers. (E.R. Vieira et al., 2007). As we know, Electromyogram (EMG) is to determine the natural prospective related to the activity of the muscle. The prospective are deliberated at the plane of the body nearer to a muscular reaction location or electrical action responding to the nerve's muscular stimulus. In the CNC machine work centres, the EMG action of the neck, shoulder, arm muscles, and spine are critically analyzed during the operation of the controls and viewing the display.

WRMSD is the indication of a twinge, sense, and rigidity, then weakness at the end, which depends on a different kind of disarray in the body spot (Gerr et al., 1991; Rempel et al., 1992). WRMSD signs are job-related, for example, the Video Display Unit (VDU). The worker states muscular sign at the higher extremity, neck, and shoulders (Hagberg and Wegman, 1987). Repeated or constant muscle action and work in which identical motor units are in use widely also frequently having a little difference with the operational condition, muscular exhaustion is expected to be increased. (Julia Faucett et al., 2002). Constant muscle masses in the forearm, besides as a non-neutral position, are connected with the muscular distress (Karlqvist et al., 1996; Jensen et al., 1998; Cooper and Straker, 1998).

Prominent muscular weight act on the muscles of the forearm, similar to monotony at wrist actions also a large spot, expose at wrist action connected to a muscular distress (Marras and Schoenmarklin, 1993; Ranney et al., 1995; Bernard, 1997; Viikari Juntura and Silverstein, 
1999). The control makes use of the lengthy key to move to the creation, vigor spot, and a regular amplification in rigidity at the last part of the key, while in a move, linked with a reducing hand signal (Rempel et al., 1999).

More than two-thirds of work-related confusion accepted in France, occupational musculoskeletal confusion present in the higher extremity. Which mostly persuades the biomechanical aspect of the recurring movement, exhausting attempt, and intense joint position (Aptel et al., 2002). The peril of musculoskeletal disarray presents large amongst employees who utilize computers in an uncomfortable situation for an extended period (Ortiz-Herna'ndez et al., 2003).

The peril of musculoskeletal disarray is high amongst the employees who utilize computers for an extended period of an uncomfortable situation (Ortiz Hernandez et al., 2003). The monitor positioned well within an angle of $15^{\circ}$ higher than or lower than the favored line of sight. That differs in both ways is evenly tolerable (Grandjean 1988). The user felt high distress when seen upward of a secure substance than when they glanced at the same, but in a sliding angle. The comfy stare angle for a closer job extends beyond descending from the favored line of sight than it performs ascendant. (Menozzi et al., 1992).

Electromyography (EMG) aimed at electrical indication study through muscle retrenchment. The signal of the muscles connected at retrenchment muscles (Solomonow et al., 1995). vision, actions alike, but in invalidate way comparable effect is not acceptable. $15^{\circ}$ of motionless flexion causes no distress or a high EMG appraisal in the following 6 hours from exposure (Chaffin, 1973). Simple $3^{\circ}$ of addition in viewing monitor effect in amplified distress (Kumar, 1994). To prevent the musculoskeletal distraction in the VDT facility, It is suggested to obtain a better position a little incline towards the top point of the monitor (Ewa Gustafsson et al., 2003). Both the whole period of stationary muscle pressure and how many times the muscle pressure drop less than $1 \%$ (MVC) maximal voluntary contraction linked at the muscular indication (Veiersted 1993).

The neck happens to be rigid further if the display location elevates. The highest position effected at Ear-Eye row above $15^{\circ}$ higher than the horizontal (Villanueva et al., 1996). The head rigid posture marks in the few movements of the trapezius muscles and larger movement of the sternomastoid (Grey, 1966). Lower screen position permits an extensive range of secure neck position though a consent ocular ease (Ankrum and Nemeth, 1995). The feature does not comparatively react to exhaustion, quantitatively or their reaction pursues a model of little variation which is tough to state, it is viable that if the entire reaction is 
allocated a worth of $100 \%$. Yet less probability will then signify a relatively higher proportion of energy exhaustion (Kumar, 2006).

The present study aims to appreciate the optimal position of control and display through the role and consequence of various muscle clusters while working in $\mathrm{CNC}$ machines, and for improving the fitness of the workers job location.

\section{MATERIAL AND METHODS}

\section{Subjects}

The study conducted in a leading Public Sector Industry in India having a big CNC work centre with different model CNC machines. Performed the study on the subjects not habituated to operate the $\mathrm{CNC}$ machines. Considering a large number of intake of fresh skilled employees in various production facilities, twenty healthy subjects (males) from the new entrants volunteered for this study. The entire group of people involved in the examination is not having a noted case of major neck or upper extremity wounds, sting also distress during previous six month. Consent was obtained from all subjects before they participated in the study. The subject's data were recorded and summarized in Table 1.

\section{Muscles}

Selected three muscles for evaluating the operation associated with the Control Panel Upper Trapezius, Deltoid and Biceps, similarly selected four muscles for the Display, - Upper Trapezius, Lower Trapezius, Sternocleidomastoid, and Erector Spinae, thus six most important steady muscles (Figure 1) for the neck and shoulder position were chosen. All the muscles are monitored simultaneously, and recorded unilaterally, since the change in experimental conditions is only in the vertical direction. Thus the obtaining reference is common to both studies (control and display) and the experimental data recording carried out.

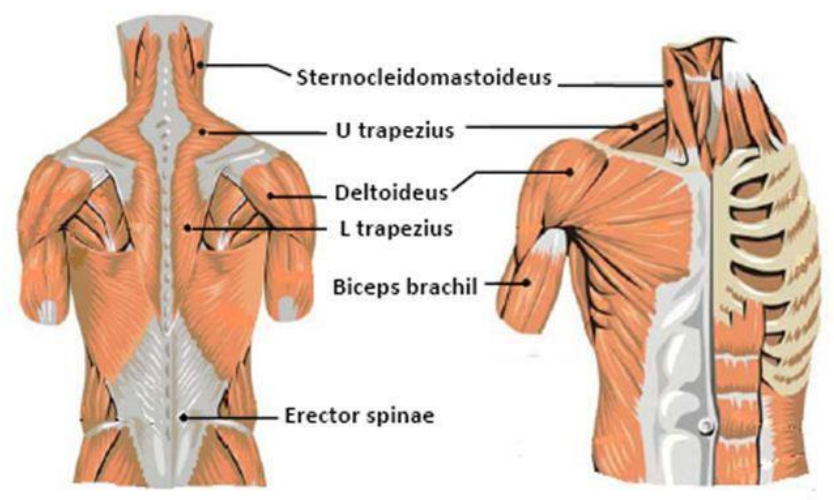

Figure 1 Muscles took for study 
Table 1 Subject information summary

\begin{tabular}{|c|c|c|c|c|}
\hline Sl. No & Subject & $\begin{array}{c}\text { Age } \\
\text { (years) }\end{array}$ & $\begin{array}{c}\text { Weight } \\
\text { (kg) }\end{array}$ & $\begin{array}{c}\text { Height } \\
\text { (cm) }\end{array}$ \\
\hline 1 & Subject-1 & 26 & 72 & 171 \\
\hline 2 & Subject-2 & 24 & 80 & 170 \\
\hline 3 & Subject-3 & 25 & 66 & 161 \\
\hline 4 & Subject-4 & 24 & 64 & 165 \\
\hline 5 & Subject-5 & 24 & 63 & 165 \\
\hline 6 & Subject-6 & 25 & 60 & 160 \\
\hline 7 & Subject-7 & 27 & 62 & 162 \\
\hline 8 & Subject-8 & 25 & 63 & 161 \\
\hline 9 & Subject-9 & 24 & 65 & 168 \\
\hline 10 & Subject-10 & 28 & 65 & 167 \\
\hline 11 & Subject-11 & 27 & 64 & 163 \\
\hline 12 & Subject-12 & 25 & 62 & 162 \\
\hline 13 & Subject-13 & 26 & 61 & 164 \\
\hline 14 & Subject-14 & 26 & 63 & 167 \\
\hline 15 & Subject-15 & 25 & 68 & 172 \\
\hline 16 & Subject-16 & 27 & 67 & 165 \\
\hline 17 & Subject-17 & 25 & 64 & 167 \\
\hline 18 & Subject-18 & 24 & 64 & 164 \\
\hline 19 & Subject-19 & 26 & 67 & 162 \\
\hline 20 & Subject-20 & 24 & 70 & 170 \\
\hline & Mean & 25.3 & 65.5 & 165.3 \\
\hline & SD & 1.22 & 4.51 & 3.58 \\
\hline & & & & \\
\hline
\end{tabular}

\section{Experimental work station}

The study conducted at the CNC machine shop, and set the workstation for EMG examination (Figure 2a), the control panel and display were set at five height levels for the study. The height is arrived based on the 95th percentile of Elbow Rest Height for the midpoint of the Control Panel, and 95th percentile for Eye Height for the top of the Display. The anthropometric data point collected from the "National Ergonomic Database for the Indian Male Population" developed at the Industrial Design Centre, Indian Institute of Technology, Bombay, in 1992. For evaluating the muscle activity two-level above and two levels below taken from the mid point. The control panel height is set as $85.6 \mathrm{~cm}, 90.6 \mathrm{~cm}$, $95.6 \mathrm{~cm}, 100.6 \mathrm{~cm}$ and $105.6 \mathrm{~cm}$. similarly; the top of the display is set at five height as $133.4 \mathrm{~cm}, 138.4 \mathrm{~cm}, 143.4 \mathrm{~cm}, 148.4 \mathrm{~cm}$, and $153.4 \mathrm{~cm}$. The illumination in the experimental room is kept constant as in the shop floor, eliminating the reflection, and glare in the visual field. 


\section{Experimental condition}

Maximal Voluntary Contraction (MVC) performed was for 60 minutes to get initial reference values for all the six muscles. Then the subjects were asked to perform a single-hand operation, first, use the control panel and later observe the display for five heights. The entire subject has to operate the control panel continuously for three minutes at each height, with a rest for one minute between the changes. The same procedure has to follow in the case of viewing the display (Figure 2). Electromyogram recorded 3 times at every height, and one minute relaxes allowed after every operation. The same procedure followed for viewing the display.

\section{EMG recording}

BIOPAC Systems(Figure 2b), intended for measuring the range of facts covering EMG, breating, pulsation, EEG, hotness, movement of eye, skin conductance, etc., of a living human being with AcqKnowledge software used for data acquisition. EMG graph and the corresponding values for the six muscles of all the twenty subjects recorded as per the experimental protocol. ( Biceps, Upper Trapezius, Lower Trapezius, Sternocleidomastoid, Deltoid, and the Erector Spinae muscles) for the neck and shoulder posture Figure 4.
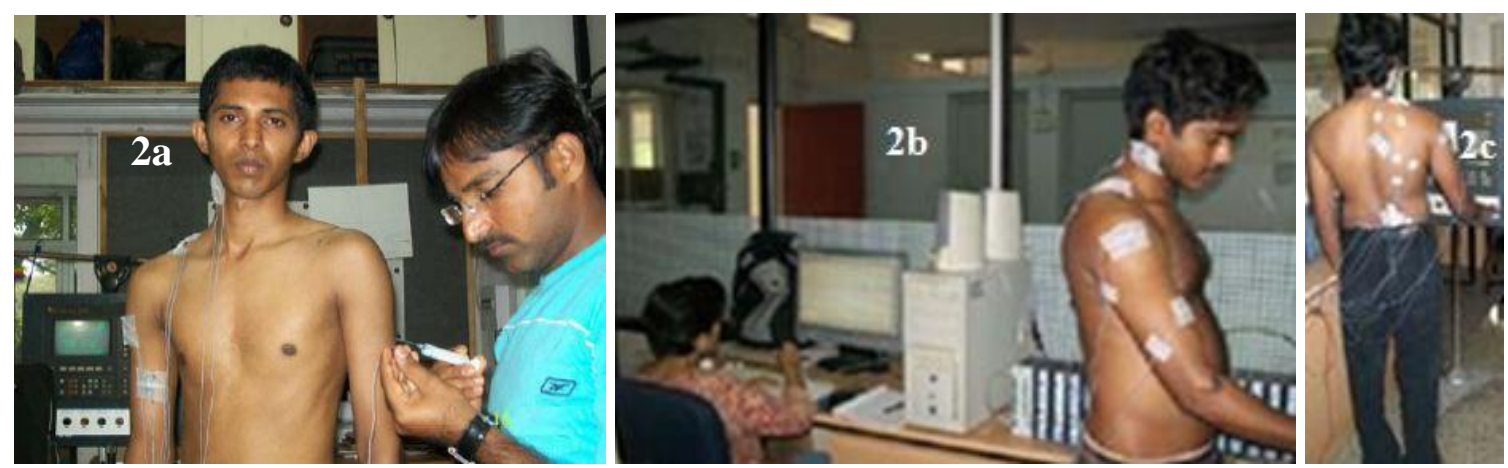

Figure 2 EMG Study at the CNC Workstation

2a CNC Work station \& a Subject

2b EMG Recording $r$

2c Electrode Placement

All the twenty subjects performed CNC machine activity as per the experimental protocol for both the control panel and display separately each for five different heights, A sample raw data obtained for a subject is presented in Figure 3 and Table 2. 


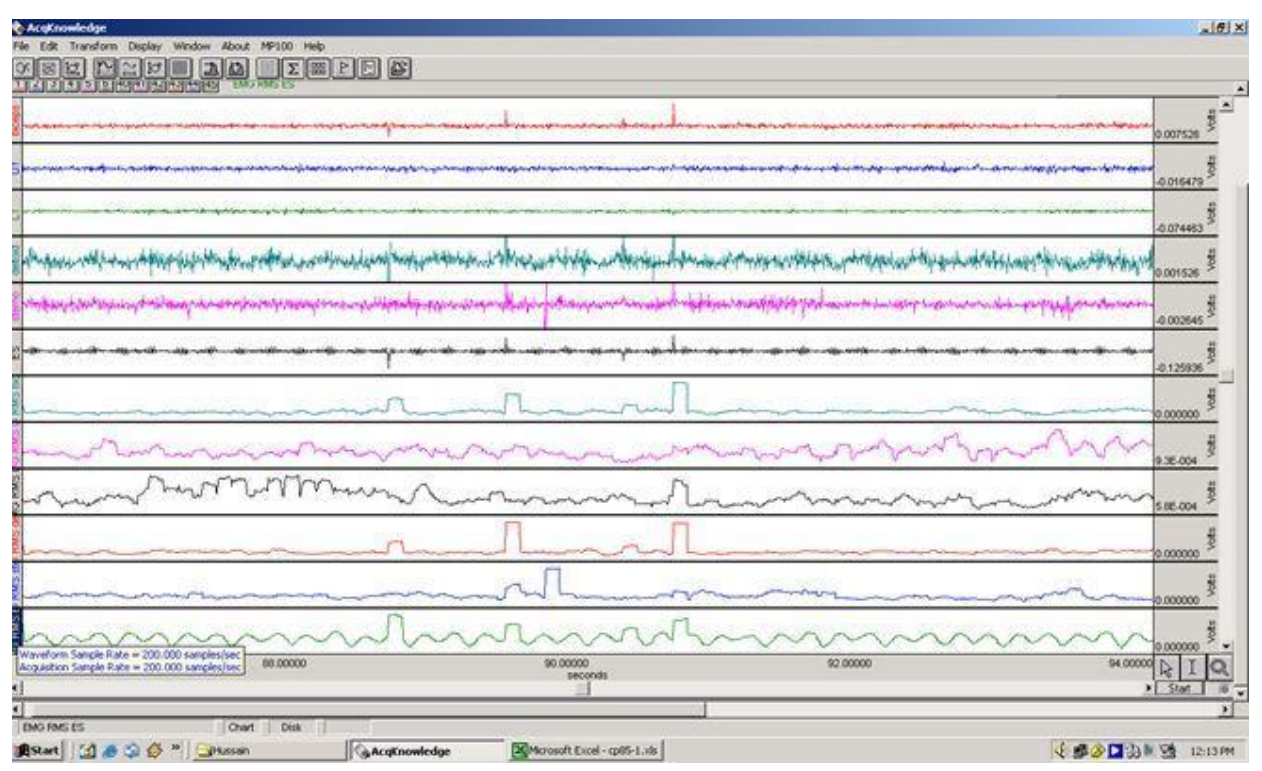

Figure 3 EMG Signal Recorded for a Subject

Table 2 EMG values recorded (Volts)

\begin{tabular}{|l|c|c|c|c|c|c|c|c|c|c|c|}
\hline Biceps & UT & LT & Deltoid & Sterno & ES & $\begin{array}{c}\text { EMG } \\
\text { RMS } \\
\text { biceps }\end{array}$ & $\begin{array}{c}\text { EMG } \\
\text { RMS } \\
\text { UT }\end{array}$ & $\begin{array}{c}\text { EMG } \\
\text { RMS } \\
\text { LT }\end{array}$ & $\begin{array}{c}\text { EMG } \\
\text { RMS } \\
\text { deltoid }\end{array}$ & $\begin{array}{c}\text { EMG } \\
\text { RMS } \\
\text { sterno }\end{array}$ & $\begin{array}{c}\text { EMG } \\
\text { RMS } \\
\text { ES }\end{array}$ \\
\hline 0.0109 & 0.0115 & -0.035 & 0.0027 & 0.0018 & 0.0073 & 0.00064 & 0.0017 & 0.0009 & 0.0013 & 0.0007 & 0.0190 \\
\hline 0.0109 & 0.0036 & -0.037 & 0.0033 & 0.0015 & 0.0112 & 0.00063 & 0.0020 & 0.0009 & 0.0013 & 0.0007 & 0.0184 \\
\hline 0.0109 & 0.0076 & -0.036 & 0.0033 & 0.0018 & -.0003 & 0.00036 & 0.0019 & 0.0008 & 0.0004 & 0.0006 & 0.0070 \\
\hline 0.0106 & 0.0076 & -0.036 & 0.0027 & 0.0009 & -.0024 & 0.00034 & 0.0019 & 0.0008 & 0.0004 & 0.0006 & 0.0072 \\
\hline 0.0103 & 0.0091 & -0.036 & 0.0036 & 0.0015 & 0.0152 & 0.00035 & 0.0019 & 0.0008 & 0.0004 & 0.0006 & 0.0075 \\
\hline 0.0109 & 0.0073 & -0.037 & 0.0030 & 0.0012 & 0.0039 & 0.00034 & 0.0019 & 0.0008 & 0.0004 & 0.0005 & 0.0073 \\
\hline 0.0103 & 0.0051 & -0.036 & 0.0039 & 0.0003 & -.0058 & 0.00035 & 0.0020 & 0.00087 & 0.0004 & 0.0006 & 0.0076 \\
\hline 0.0106 & 0.0070 & -0.035 & 0.0033 & 0.0018 & 0.0064 & 0.00032 & 0.0019 & 0.00087 & 0.0004 & 0.0006 & 0.0075 \\
\hline 0.0109 & 0.0106 & -0.036 & 0.0030 & 0.0021 & 0.0180 & 0.00031 & 0.0020 & 0.00087 & 0.0004 & 0.0006 & 0.0078 \\
\hline 0.0100 & 0.0097 & -0.035 & 0.0021 & 0.0021 & 0.0061 & 0.00035 & 0.0020 & 0.00088 & 0.0004 & 0.0006 & 0.0078 \\
\hline 0.0106 & 0.0082 & -0.035 & 0.0048 & 0.0012 & -.0112 & 0.00035 & 0.0020 & 0.00090 & 0.0005 & 0.0006 & 0.0084 \\
\hline 0.0106 & 0.0057 & -0.036 & 0.0039 & 0.0015 & 0.0054 & 0.00035 & 0.0021 & 0.00089 & 0.0006 & 0.0006 & 0.0081 \\
\hline 0.0109 & 0.0079 & -0.036 & 0.0051 & 0.0030 & 0.0280 & 0.00034 & 0.0021 & 0.00089 & 0.0007 & 0.0007 & 0.0094 \\
\hline 0.0097 & 0.0085 & -0.037 & 0.0030 & 0.0003 & 0.0091 & 0.00038 & 0.0020 & 0.00095 & 0.0007 & 0.0007 & 0.0092 \\
\hline 0.0103 & 0.0097 & -0.037 & 0.0036 & 0.0024 & -.0137 & 0.00036 & 0.0020 & 0.00096 & 0.0007 & 0.0007 & 0.0102 \\
\hline 0.0109 & 0.0054 & -0.036 & 0.0036 & 0.0009 & 0.0054 & 0.00037 & 0.0021 & 0.00094 & 0.0006 & 0.0007 & 0.0100 \\
\hline 0.0103 & 0.0085 & -0.038 & 0.0045 & 0.0015 & 0.0280 & 0.00034 & 0.0020 & 0.00101 & 0.0007 & 0.0007 & 0.0110 \\
\hline
\end{tabular}

\section{Maximal voluntary contraction (MVC)}

To make possible comparisons among the workers to be examined, muscles, and various operational condition, the EMG is regularized using Maximal Voluntary Contraction. MVC is measured at the beginning of the experiment to get reference values for each muscle and 
the muscle activity for all the six muscles recorded. The mean peak values are taken as MVC. Figure. 4, and Table 3.

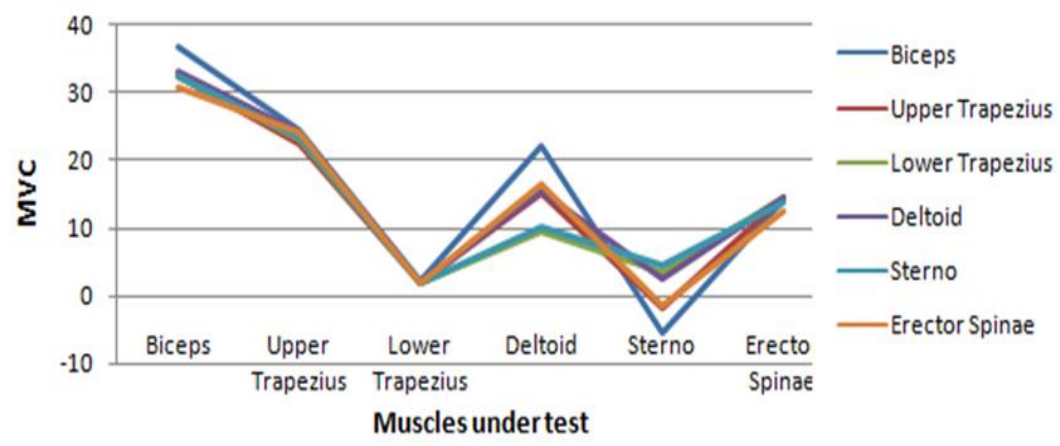

Figure 4 MVC for Subject 1

Table 3 Maximal Voluntary Contraction (MVC) for Subject 1

\begin{tabular}{|l|c|c|c|c|c|c|}
\hline MVC & Biceps & $\begin{array}{c}\text { Upper } \\
\text { Trapezius }\end{array}$ & $\begin{array}{c}\text { Lower } \\
\text { Trapezius }\end{array}$ & Deltoid & Sterno & $\begin{array}{c}\text { Erector } \\
\text { Spinae }\end{array}$ \\
\hline Biceps & 36.68253 & 24.29524 & 2.16847 & 22.01497 & -5.42706 & 14.10675 \\
\hline $\begin{array}{l}\text { Upper } \\
\text { Trapezius }\end{array}$ & 32.33105 & 22.57039 & 1.87088 & 15.10449 & -1.66665 & 14.62031 \\
\hline Sterno & 32.22928 & 23.1699 & 1.97499 & 9.614809 & 3.60908 & 14.57957 \\
\hline $\begin{array}{l}\text { Lower } \\
\text { Trapezius }\end{array}$ & 32.87822 & 23.78590 & 1.78487 & 15.43734 & 2.41202 & 14.28411 \\
\hline $\begin{array}{l}\text { Erector } \\
\text { Spinae }\end{array}$ & 32.21580 & 23.23389 & 1.84738 & 10.00577 & 4.37299 & 13.83972 \\
\hline Deltoid & 30.80816 & 24.16845 & 1.97779 & 16.58193 & -1.50616 & 12.49308 \\
\hline
\end{tabular}

\section{Study of muscles activity}

EMG plotted for all the six muscles for all subjects at five different levels of heights, recorded three times with the relax interval of 1 minute after each operation for all the five heights of control panel and five heights of the display. The EMG readings recorded from the middle of each 3 minutes window frame. From the EMG data, the \% MVC calculated for all the subjects. The \% MVC calculated as EMG RMS*100 / MVC and the graphs plotted. The mean \% MVC given the overall activity of the muscles at each control panel height, and at each display height. 
Table 4 Mean \% MVC for Control Panel and at Different height

\begin{tabular}{|c|c|c|c|c|c|c|}
\hline $\begin{array}{c}\text { Panel } \\
\text { height }\end{array}$ & Biceps & $\begin{array}{c}\text { Upper } \\
\text { Trapezius }\end{array}$ & $\begin{array}{c}\text { Lower } \\
\text { Trapezius }\end{array}$ & Deltoid & Sterno & $\begin{array}{c}\text { Erector } \\
\text { Spinae }\end{array}$ \\
\hline $85 \mathrm{~cm}$ & 2.02862 & 2.23109 & 2.35621 & 2.00639 & 2.16738 & 2.69399 \\
\hline $90 \mathrm{~cm}$ & 1.73309 & 2.09771 & 1.74882 & 1.35671 & 1.35671 & 2.58647 \\
\hline $95 \mathrm{~cm}$ & 1.46002 & 1.90479 & 2.27470 & 1.65568 & 2.11831 & 2.63006 \\
\hline $100 \mathrm{~cm}$ & 1.53280 & 1.87760 & 2.17098 & 1.41621 & 2.06037 & 2.27857 \\
\hline $105 \mathrm{~cm}$ & 1.76123 & 2.40635 & 2.4766 & 1.65814 & 1.89378 & 2.30665 \\
\hline
\end{tabular}

Table 5 Mean \% MVC for Display at Different height

\begin{tabular}{|c|c|c|c|c|c|c|}
\hline $\begin{array}{c}\text { Display } \\
\text { height }\end{array}$ & Biceps & $\begin{array}{c}\text { Upper } \\
\text { Trapezius }\end{array}$ & $\begin{array}{c}\text { Lower } \\
\text { Trapezius }\end{array}$ & Deltoid & Sterno & $\begin{array}{c}\text { Erector } \\
\text { Spinae }\end{array}$ \\
\hline $133 \mathrm{~cm}$ & 2.49362 & 2.61448 & 2.67421 & 2.49309 & 3.06892 & 3.12614 \\
\hline $138 \mathrm{~cm}$ & 2.40026 & 2.569007 & 2.52569 & 2.61719 & 3.21045 & 3.19002 \\
\hline $143 \mathrm{~cm}$ & 2.47600 & 2.30541 & 3.15740 & 2.46489 & 3.43368 & 3.43141 \\
\hline $148 \mathrm{~cm}$ & 2.63815 & 2.42218 & 2.93302 & 2.58657 & 3.11301 & 3.05918 \\
\hline $153 \mathrm{~cm}$ & 2.25662 & 2.69148 & 2.40369 & 2.03099 & 3.13563 & 2.72951 \\
\hline
\end{tabular}

\section{RESULTS AND DISCUSSION}

\section{Graphical analysis}

Based on the results, the muscle activity is significantly higher during the dynamic motion of the subjects, as the fingers move on the keys and the eyes move both keys and display. But comparatively lesser in the static position of the subjects

\section{\% MVC for control panel}

Subjects 1, 15, and 20 showed a reduction in Sternocleidomastoid muscle activity at the heights $95 \mathrm{~cm}$ and $100 \mathrm{~cm}$ but no change in other muscles (Figure 5a). Since none of the arm muscles showed any change, this appears control panel height not preferred for this subject, however from looking at the control panel (e.g. to choose the control to be operated), $95 \mathrm{~cm}$ to $100 \mathrm{~cm}$ seems to be preferred by these subjects.

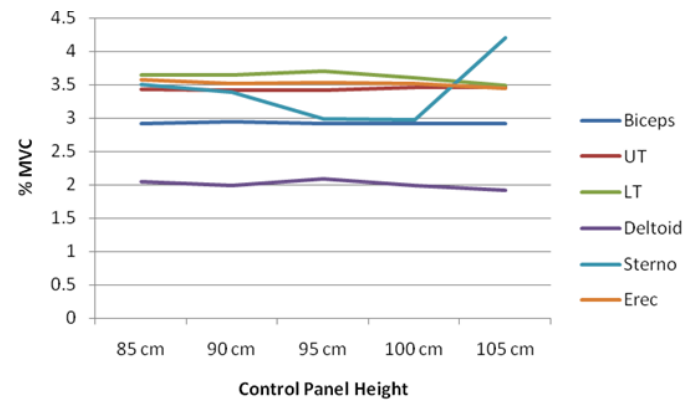

Figure 5a \% MVC for Subjects 1, 15, 20

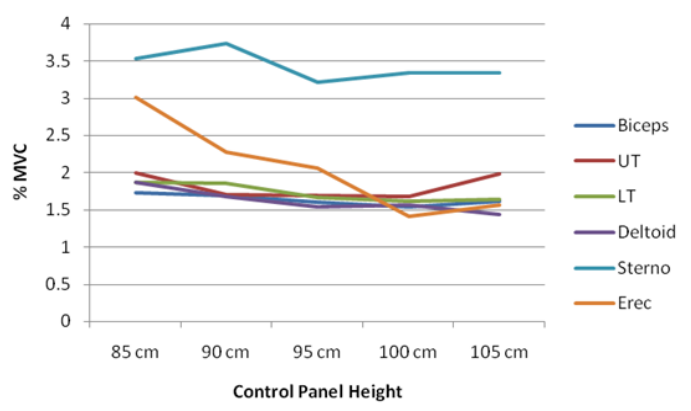

Figure 5b \% MVC for Subjects 2, 9, 17 
Subjects 2, 9, and 17 showed a reduction in Biceps activity at heights $95 \mathrm{~cm}$ and $100 \mathrm{~cm}$ and a notable reduction in Erector Spinae muscles flattening at $100 \mathrm{~cm}$, but no change in welldefined muscles (Figure $5 \mathrm{~b}$ ). Thus $95-100 \mathrm{~cm}$ is a preferred height for these subjects.

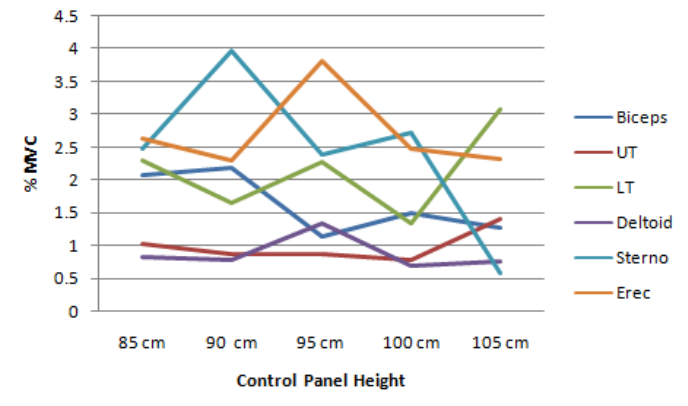

Figure 5c \% MVC for Subjects 3, 8, 12,19

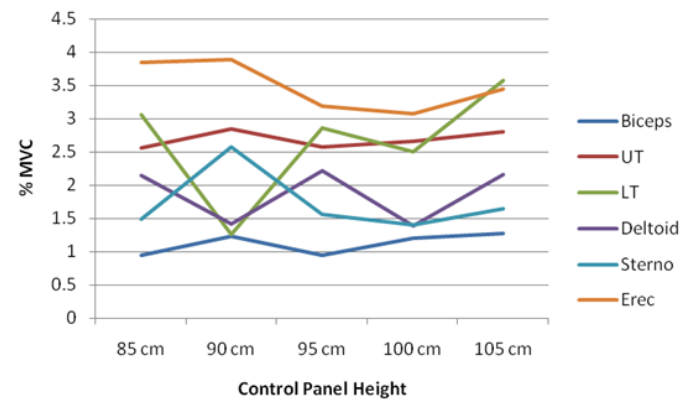

Figure 5d \% MVC for Subjects 4,10,14,16

Subjects 3, 8, 12, and 19 showed a reduction in Sternocleidomastoideus, Biceps, and Upper Trapezius muscle activity at the heights $95 \mathrm{~cm}$ and $100 \mathrm{~cm}$, but Lower trapezius, Deltoid, and Erector Spinae activity increased in $95 \mathrm{~cm}$ and reduction in $100 \mathrm{~cm}$ (Figure 5c). Since the arm positioning-related muscles showed a change, $100 \mathrm{~cm}$ seems to be preferred by these subjects.

Subjects 4, 10, 14, and 16 showed a reduction in Sternocleidomastoideus, Erector Spinae muscle activity for heights $95 \mathrm{~cm}$ and $100 \mathrm{~cm}$, and reduction in Biceps and Upper Trapezius for heights $95 \mathrm{~cm}$ and increase for heights $100 \mathrm{~cm}$ but Deltoid and Lower Trapezius activity increased in $95 \mathrm{~cm}$ and reduction in $100 \mathrm{~cm}$ (Figure 5d). Since the arm positioning-related muscles showed a change, $95 \mathrm{~cm}-100 \mathrm{~cm}$ seems to be preferred by these subjects.

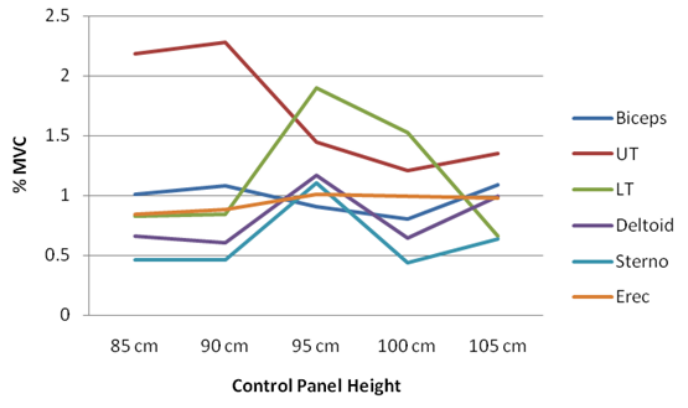

Figure 5e \% MVC for Subjects 5, 7, 18

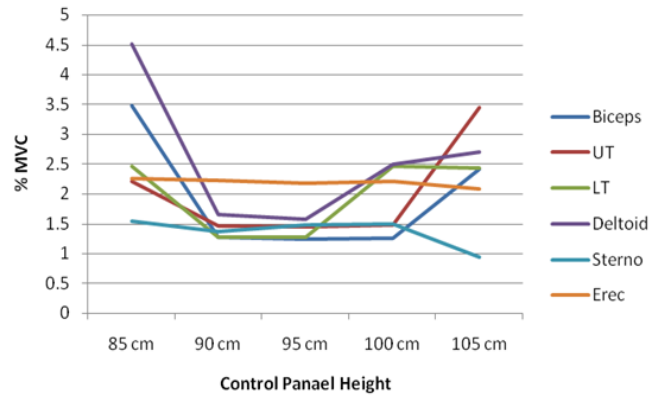

Figure 5f \% MVC for Subjects 6, 11, 13

Subjects 5, 7, and 18 showed a reduction in Biceps and Upper Trapezius muscle activity for heights $95 \mathrm{~cm}$ and $100 \mathrm{~cm}$. Sternocleidomastoidus, Deltoid, and Lower Trapezius muscle activity increased at $95 \mathrm{~cm}$ and reduced at $100 \mathrm{~cm}$ (Figure 5e). As most of the muscles showed a low at $100 \mathrm{~cm}$, this seems to be the preferred height for these subjects. 
Subjects 6, 11, and 13 showed a reduction in Deltoid and Lower Trapezius muscle activity for heights $90 \mathrm{~cm}-95 \mathrm{~cm}$ and an increase at $100 \mathrm{~cm}$. Upper Trapezius and Biceps muscle showed a trough at $90-95-100 \mathrm{~cm}$ height(Figure 5f). Thus $90 \mathrm{~cm}-95 \mathrm{~cm}$ is the preferred height for these subjects.

To Sum up for control panel, when all the scores of the subjects are aggregate, it may say that $95 \mathrm{~cm}(90-100 \mathrm{~cm})$ appears to be the optimum level for the midpoint of the control panel.

\section{\% MVC for display}

Figure 6a \% MVC for Subjects 1, 5, 15, 20 Figure 6b \% MVC for Subjects 2, 9, 17

Subjects 1, 15, and 20 showed a reduction in the Biceps, Upper Trapezius, and Deltoid muscles activity at the height of $143 \mathrm{~cm}$, and an increase in Erector Spinae and Sternocleido Mastoidus muscles in the same height of $143 \mathrm{~cm}$, but no change in other muscles (Figure 6a). Thus we may conclude that none of the display heights particularly favorable to these subjects, considering Upper Trapezius, $143 \mathrm{~cm}$ seems to be preferred.
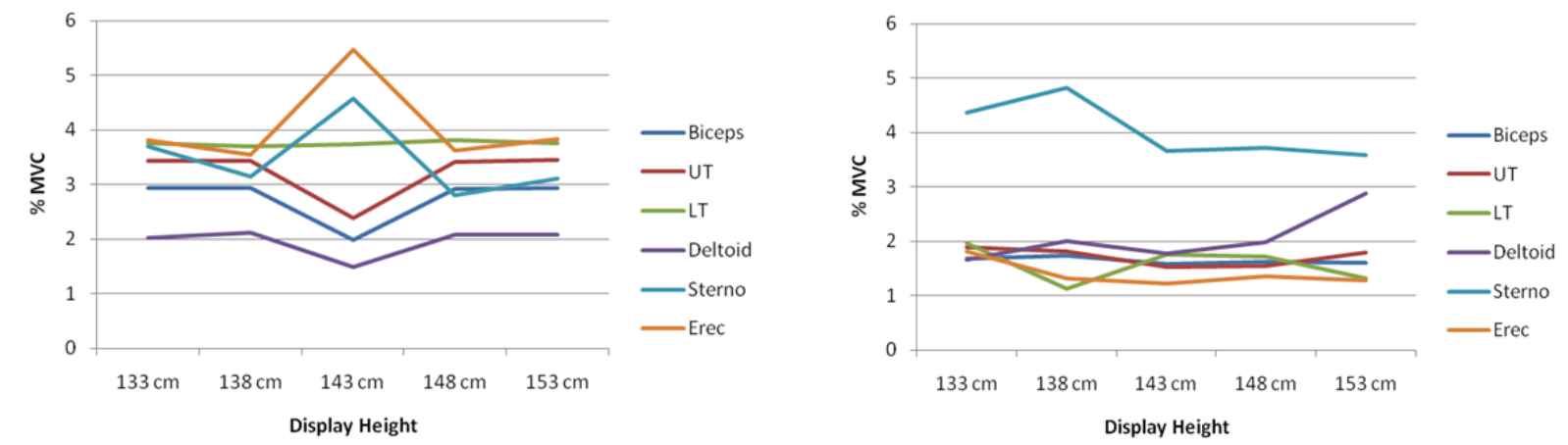

Subjects 2, 9, and 17 showed a notable reduction in Sternocleidomastoid muscle activity at the $143 \mathrm{~cm}-148 \mathrm{~cm}$ range and no change in other muscles except a rise in Biceps activity at $153 \mathrm{~cm}$ height(Figure 6b). Thus it may be said that the height range of $143-148 \mathrm{~cm}$ is optimum for these subjects (Biceps activity is not very significant for display).

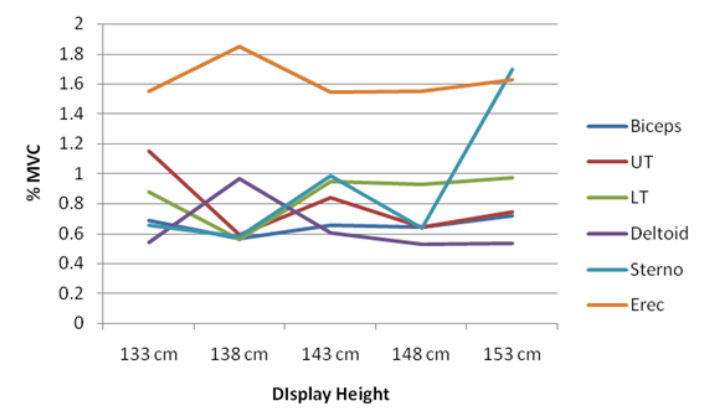

Figure 6c \% MVC for Subjects 3, 8, 12,19

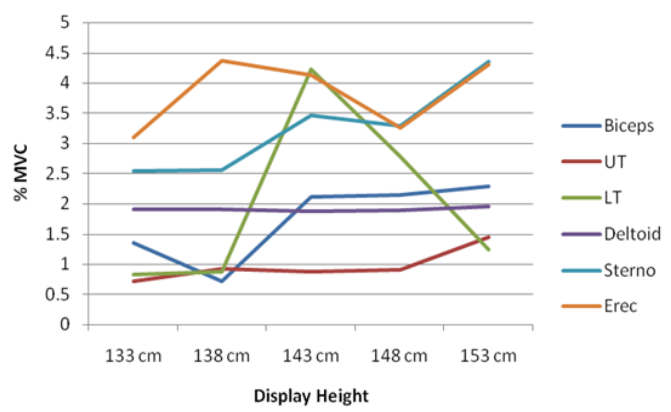

Figure 6d \% MVC for Subjects 4,19,14,16 
Subjects 3, 8, 12, and 19 showed marked reduction in Deltoid and Erector Spinae muscle activity in the $143 \mathrm{~cm}-148 \mathrm{~cm}$ range, Sternocleidomastoidus, and Upper Trapezius activity increased at $143 \mathrm{~cm}$ and reduced at $148 \mathrm{~cm}$, but no change in other muscles in the $143-148$ $\mathrm{cm}$ height (Figure 6c). Thus it may be said that heights of 143-148 $\mathrm{cm}$ are optimum for the display for these subjects.

Subjects 4, 10, 14, and 16 showed a reduction in Erector Spinae muscle activity at $148 \mathrm{~cm}$ height, while Sternocleidomastoidus activity is less in $133 \mathrm{~cm}-138 \mathrm{~cm}$ range, increased between $143 \mathrm{~cm}-148 \mathrm{~cm}$ range, and further increased at $153 \mathrm{~cm}$ height. Lower Trapezius activity is a peak at $143 \mathrm{~cm}$, with no change in Deltoid and other muscles (Figure 6d). Thus it appears that a range of $143 \mathrm{~cm}-148 \mathrm{~cm}$ is optimum for these subjects.

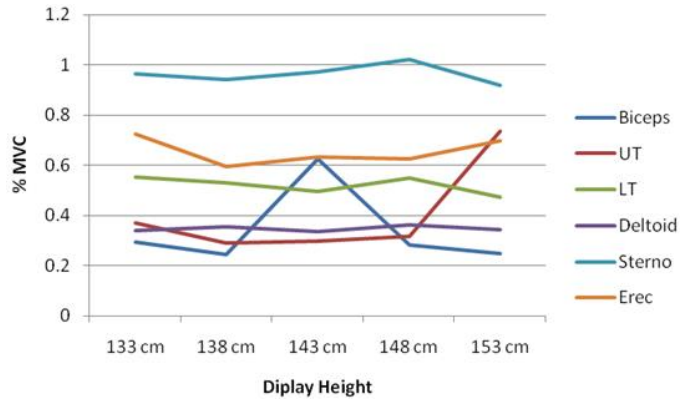

Figure 8e \% MVC for Subjects 5, 7, 18

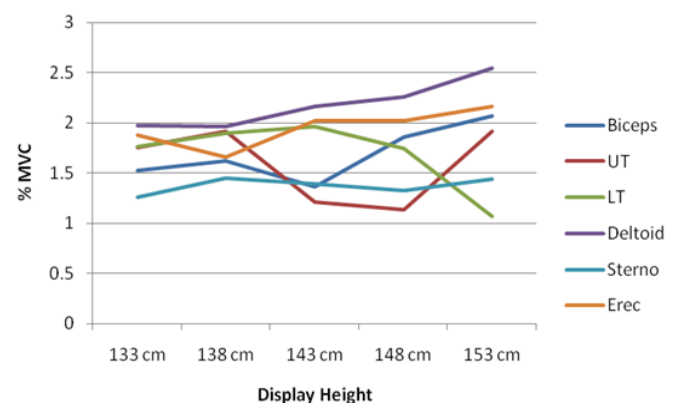

Figure 8f \% MVC for Subjects 6, 11, 13

Subjects 5, 7, and 18 showed an increase at $153 \mathrm{~cm}$ height in Upper Trapezius muscle activity. Other than Biceps (not relevant for display), no change in any other muscle (Figure 6e). Thus the height below $153 \mathrm{~cm}$ is optimum for these subjects.

Subjects 6, 11, and 13 showed a reduction in Upper Trapezius muscle activity in the 143-48 $\mathrm{cm}$ range, with no change in Sternocleidomastoideus activity (barring a mild dip at $148 \mathrm{~cm}$ ). Biceps, Deltoid, and Erector Spinae muscle activity increased from $143 \mathrm{~cm}$ upwards. Lower Trapezius showed slightly increased activity at $138 \mathrm{~cm}-143 \mathrm{~cm}$ and then reduced at the 148 $\mathrm{cm}-153 \mathrm{~cm}$ heights (Figure 6f). Thus it may be said that a height range of $143 \mathrm{~cm}-148 \mathrm{~cm}$ is optimum for the display for these subjects. To Sum up for display, when all the scores of the subjects are aggregate, it may say that the range $143 \mathrm{~cm}-148 \mathrm{~cm}$ appears to be the optimum range for the midpoint of the display. 


\section{CONCLUSION AND RECOMMENDATION}

\section{Conclusion}

In the examination, change in muscle activity relatively small in all the six muscles examined. However, the actual workplace situation takes for evaluating the ergonomic impact. The cumulative activity, borne for a shift, a week, a month, or a year to be considered. Muscle activity may increase in the worker's repetitive head/finger movement. The optimum height range of the midpoint of the control panel recommended as $95-100 \mathrm{~cm}$, and optimum height for the top point of the display as $143-148 \mathrm{~cm}$, and thus to reduce the static muscular load on the operators, provide a more ergonomic design of the $\mathrm{CNC}$ operator interface.

\section{Recommendations}

1. Detach the control panel from the main machine and fix it on a flexible boom, to permit the boom movement to the individual operator and the task requirement. The center point of the most frequently operated keys should be about $50 \mathrm{~cm}$ below the top of the display.

2. Set the center point of the most frequently operated keys at $95 \mathrm{~cm}-100 \mathrm{~cm}$, and the top of the display at $143 \mathrm{~cm}-148 \mathrm{~cm}$ from the floor level, for the permanently fixed control panel and display. This will help in reducing discomfort.

\section{ACKNOWLEDGEMENTS}

Sincere gratitude for the extensive support and guidance by

1. Dr. K. Sankaranarayanasamy, National Institute of Technology, Puducherry.

2. Dr. Gaur G. Ray, Department of Industrial Design Centre, Indian Institute of Technology Bombay, Mumbai.

3. Dr. A.K. Ganguli, National Model Centre for Occupational Health, Bharat Heavy Electricals Ltd., Tiruchirappalli.

4. Dr. Swati Pal, Department of Industrial Design Centre, Indian Institute of Technology Bombay, Mumbai,

\section{REFERENCES}

Ankrum, D.R. and Nemeth, K.J.(1995), Posture, Comfort and Monitor Placement. Ergonomics in Design; April, 7-9. 
Aptel, M., Aublet-Cuvelier, A., Cnockaert, J.C. (2002), Work-related musculoskeletal disorders of the upper limb. Joint Bone Spine; 69:546-555.

Bernard, B.P., Sauter, S.L., Fine, L., Petersen, M., Hales, T. (1993). Health Hazard Evaluation Report HETA; 90-013 (LA Times).

Bernard, B (1997). A critical review of epidemiological evidence for work-related musculoskeletal disorders of the neck, upper extremity, and low buck, US Department of Health and Human Services; 97-141.

Chaffin, D.B. (1973), Localized muscle fatigue -definition and measurement, Journal of Occupational Medicine; 15: 346-354.

Cooper, A. and Straker, L. (1998), Mouse versus keyboard use - a comparison of shoulder muscle load, International Journal of Industrial Ergonomics; 22: 351-357.

Ewa Gustafsson, Mats Hagberg (2003), Computer mouse use in two different hand positions:exposure, comfort, exertion productivity Applied Ergonomics; 34: 107-113.

Faucett, J., Rempel, D.(1994). VDT-related musculoskeletal symptoms: interactions between work posture and psychosocial work factors. Am. J. Ind. Med.; 26: 597-612.

Grandjean, E. (1974), Ergonomics in Computerized Offices, (Taylor \& Francis, London); 3: $128-135$

Gerr, F., Letz, R., Landrigan, P.J.(1991). Upper extremity musculoskeletal disorders of occupational origin. Ann. Rev. Public Health; 12:543-566

Grey, F.E., Hanson, J.A., and Jones, F.P. (1966), Postural Aspects of Neck Muscle Tension. Ergonomics; 9(3): 245-256.

Hagberg, M., Wegman, D.H. (1987). Prevalence rates and odds ratios of shoulder-neck diseases in different occupational groups. Br. J.Ind. Med.; 44:602-610

Jensen, C., Borg, V., Finsen, L., Hansen, K., Juul-Kristensen, B., Christensen, H. (1998). Job demands, muscle activity and musculoskeletal symptoms in relation to work with the computer mouse. Scand. J. Work Environ. Health; 24 (5): 418-424.

Julia Faucett,(2002) A test of two training interventions to prevent work-related musculoskeletal disorders of the upper extremity, Applied Ergonomics; 33:337-347

Karlqvist, L., Hagberg, M., Ko. ster, M., Wenemark, M., A nell, R. (1996). Musculoskeletal symptoms among computer-assisted design (CAD) operators and evaluation of a self-assessment questionnaire. J. Occup. Environ. Health; 2:185-194.

Kumar, S. A (1994), computer desk for bifocal lens wearers, with special emphasis on selected telecommunications tasks, Ergonomics; 37:1669-1678. 
Kumar S. (2006);Localized Muscle Fatigue: Review of three experiments Rev.bras. Fisioter; 10(1): 9-28.

Marras WS, Schoenmarklin RW(1993), Wrist motions in industry. Ergonomics; 36 (4): $342-351$

Menozzi, M., Buol, A.V., Krueger, H., Miege, C., and Pedrono, C. (1992), Fitting varifocal lenses: Strain as a function of the orientation of the eyes, Ophthalmic and Visual Optics; 3: 134-137.

Ortiz-Herna'ndez, L., Tamez-Gonza'lez, S., Matı́nez-Alca'ntara, S. MéndezRamı'rez, I., (2003) Computer use increases the risk of musculoskeletal disorders among newspaper office workers. Archives of Medical Research; 34: 331-342.

Ranney, D.A., Wells R. P., Moore, A. (1995), Upper limb musculoskeletal disorders in highly repetitive industries: precise anatomical findings. Ergonomics; 38:1408-1423.

Rempel, D.M., Harrison, R.J., Barnhardt, S.(1992). Work-related cumulative trauma disorders of the upper extremity. J. Am Med. Assoc.; 267:8-842.

Rempel, D., Tittiranonda, P., Burastero, S., Hudes, M. and So, Y. (1999), Effect of keyboard keyswitch design on hand pain. Journal of Occupational and Environmental Medicine; 41: 111-119

Sauter, S.L., Swanson, N.G. (1996), An ecological model of musculoskeletal disorders in office work. In: Moon, S.D., Sauter, S.L.(Eds.), Beyond Biomechanics: Psychosocial Musculoskeletal Disorders in Office Work. Taylor and Francis, London; 3-20.

Solomonow, M., Acierno, S. P., Baratta, R. V. (1995), “ A practical guide to electromyography for ergonomists and bio mechanists." Occupational medicine research center, Louisiana State University Health Science Department of Orthopaedics. Ch-16; 392-408.

Veiersted, K.B., Westgaard, R.H., Andersen, P. (1993). Electromyographic evaluation of muscular work pattern as a predictor of trapezius myalgia. Scandinavian Journal of Work, Environment and Health; 19:284-290.

Vieira E.R., S. Kumar (2007), Occupational risks factors identified and interventions suggested by welders and computer numeric control workers to control low back disorders in companies International Journal of Industrial Ergonomics; 37: 553-56.

Viikari-Juntura E, Silverstein B. (1999), Role of physical load factors in carpal tunnel syndrome. Scand J Work Environ Health; 25(3):163-85. 
Villanueva, M.B.G., Sotoyama, M., Jonai, H.,Takeuchi, Y. and Saito, S. (1996), Adjustment of posture and viewing parameters of the eye to changes in screen height of the visual display terminal, Ergonomics; 39:7, 933-945. 